\title{
Undergraduate student-faculty collaborative research: A pilot study exploring care of a family member with dementia
}

\author{
Theresa A. Kesseler, Lynette Rayman \\ College of Nursing and Health Professions, Valparaiso University, United States
}

Received: September 11, 2020

Accepted: November 3, 2020

Online Published: November 12, 2020

DOI: $10.5430 /$ jnep.v11n3p17

URL: https://doi.org/10.5430/jnep.v11n3p17

\begin{abstract}
Objective: Caregivers for a family member with dementia experience subtle but long-term role changes that can be attenuated with successful coping strategies. The aim of this paper is to describe an effective research initiative managed by an undergraduate student-faculty collaborative team to assess the physical, emotional, and financial effects of caregiving and identify the impact of using an adult day service.

Methods: Using the collaborative model, undergraduate nursing students led a mixed method, pilot study. Eight students, mentored by two faculty, held weekly meetings to manage the research design. After reviewing literature evidence, students developed the methodology and carried out the research. The convenience sample included 10 caregivers, each having a family member with dementia, who attended an adult day center in a rural/suburban city in the Midwest. The Kingston Caregiver Stress Scale (KCSS), a 10-item assessment of caregiver stress using a 5-point Likert scale, measured quantitative data. Two focus groups were conducted to collect qualitative data.

Results: Participants included 6 males/4 females ranging in age from 46-72 (M = 65, SD = 10.58). Participants provided care an average of 4.2 years $(\mathrm{SD}=6.0)$ and reported moderate levels of caregiving stress on the KCSS $(\mathrm{M}=30.5, \mathrm{SD}=9.7)$. Four themes emerged from focus groups: (a) common emotional responses, (b) benefits of adult day services, (c) overwhelming impact on daily life, and (d) caregiver social isolation.

Conclusions: Respite services promoted resilience through opportunities to manage self-care, to perform daily tasks, and to decrease emotional burden. Undergraduate nursing students effectively planned and implemented the research. As future practitioners, they may be more inclined to participate in best practice because of their experience on a student-faculty collaborative team.
\end{abstract}

Key Words: Dementia, Adult day services, Caregiver, Undergraduate nursing students, Student faculty collaboration

\section{INTRODUCTION}

Engaging undergraduate nursing students in student-faculty collaborative research can support the link between clinical practice and research. Independent study courses offer a mechanism to engage students in faculty-led research projects. However, there are few examples reported in the nursing literature of students leading research outside of the traditional classroom. As a STEM discipline, nursing educators should develop innovative ways of engaging undergraduate students in traditional research methods to foster

\footnotetext{
* Correspondence: Theresa A. Kesseler; Email: terry.kessler@ valpo.edu; Address: College of Nursing and Health Professions, Valparaiso University, United States.
}

Published by Sciedu Press 
future researchers and develop evidence for nursing practice. One method is to mentor students so that they can lead research projects. Evidence supports that undergraduate students have the requisite skills to be successful at designing, implementing, and evaluating research when mentored by faculty. ${ }^{[1-3]}$ While faculty mentors facilitate student success in the research process, faculty mentors may also provide a stimulus for students to pursue graduate degrees, while simultaneously introducing students to faculty roles. ${ }^{[4]}$ Using a student-faculty mentor model promotes immersion in knowledge generation, excitement about the research process, and the development of leadership skills. ${ }^{[2]}$

Throughout an undergraduate nursing program, students experience a wide variety of clinical experiences exposing them to various nursing roles and practice areas. Often times, students become excited about their clinical experiences and wish they could have additional time in those areas or raise questions about what they observed that can lead to research questions. During a clinical rotation at an adult day center for those with dementia, students were positively impacted by the care provided. They were cognizant of the demands of the caregiver role and raised questions about how respite services impacted the caregiver role. Students wanted to have a deeper understanding of the daily demands associated with providing care to a family member with dementia, and how, as future nurses, they could support caregivers.

Based on the students' clinical experiences and questions raised, the faculty and students discussed potential research projects. As a result of these discussions, the collaborative team decided to move forward with a pilot study providing students with the opportunity to lead the initiative. The aim of this paper is to describe an effective research study managed by an undergraduate student-faculty collaborative team to assess the physical, emotional, and financial effects of caregiving and identify the impact of using an adult day service.

\subsection{Dementia and the caregiver role}

To begin the process, the students completed a literature search on the caregiver role for a family member with dementia. The incidence of dementia is growing worldwide and affects about 50 million people with nearly 10 million new cases annually. ${ }^{[5]}$ In the U.S., dementia affects an estimated 5.8 million Americans, and this number is expected to rise to nearly 14 million by $2050 .{ }^{[6]}$ Dementia has ramifications for those affected as well as their family, ${ }^{[7]}$ as approximately $70 \%-80 \%$ of people with dementia reside with a family caregiver. ${ }^{[8]}$ Caregivers provide an estimated 18.6 billion hours of care and save the U.S. healthcare system nearly \$244 billion by keeping their family members at home. ${ }^{[6]}$ This cost savings alone highlights the important role that family caregivers play in dementia care.

Alzheimer's disease has a devastating impact on caregivers resulting in emotional, physical, and financial repercussions $^{[6,9]}$ that can add to psychological distress. ${ }^{[10]}$ In fact, twice as many caregivers of those with dementia indicate these difficulties. ${ }^{[6]}$ Caregivers are responsible for holistic support to family members with dementia, which limits their social activities, increases social isolation, decreases leisure activities, and adds to family distress. ${ }^{[11]}$ Physical and mental/emotional health are neglected as caregivers make the needs of their family member a priority. ${ }^{[12]}$

"Ambiguous grief" describes the experience of family members as they provide care during the course of the illness. ${ }^{[13]}$ There are repeated episodes of grief as they observe new behaviors and personality changes, including agitation, aggression, and depression. ${ }^{[14]}$ The onset of dementia is subtle which leads to assuming the role of caregiving on a gradual basis, sometimes without recognizing the process is actually occurring. ${ }^{[8]}$ Roberts and Struckmeyer coined the phrase "unexpected career of caregiver", a complex, stressful role the caregiver must balance with other demands such as jobs and child-rearing. ${ }^{[8]}$ Eventually, caregivers may provide care for a family member who no longer recognizes them, ${ }^{[7]}$ further adding to caregiver stress.

Caregiver resilience is a framework that supports using strategies to cope with situations that focus on strength instead of burden, ${ }^{[8]}$ explaining how caregivers manage the daily challenges of caring for their loved ones. Resilience is the ability to maintain normal or even enhanced daily functioning when one experiences adversity. ${ }^{[15,16]}$ Resilience consists of thriving and succeeding during the adversity and exhibiting competence to manage the situations often when others do not succeed. Respite community resources, such as adult day services (ADS), are one way that caregivers may make time for themselves and support their ability to maintain normalcy and demonstrate resiliency. ADS reduce burden and were found to lower the repercussions of physical, mental, and emotional outcomes of the caregiver role. ${ }^{[17]}$ Because of these repercussions, caregiver respite may sustain resilience throughout the continuum of care. ${ }^{[8]}$ To investigate the repercussions of being the caregiver for a family member with dementia, an undergraduate nursing student-faculty collaborative research team completed a mixed-method, pilot study to (a) assess the physical, emotional, and financial effects of being a caregiver; and (b) identify the impact of using an adult day service. 


\section{Methods}

\subsection{Design and collaborative process}

The study used a mixed method design. Qualitative and quantitative data were collected simultaneously. Simultaneous data collection lends itself to team research and allowed members of the student-faculty collaborative team to weigh both sources of data. ${ }^{[18]}$

The collaborative team consisted of eight undergraduate students ( 3 seniors, 2 juniors, and 3 sophomores) and two faculty mentors. The senior students led the team guided by the faculty mentors. Weekly meetings were held to assess goal achievement and support the students as they carried out the study. Students conducted the literature review, selected a framework, developed the methodology, carried out the data collection process, and disseminated the results.

\subsection{Sample and setting}

The convenience sample included caregivers of a family member with dementia who attended an adult day center in a rural/suburban city in the Midwest where the students had a clinical rotation. The adult day center provides services regardless of race, religion, gender, or financial means. The director of the adult day center sent a flyer, developed by the collaborative research team, as part of their monthly newsletter. The flyer invited caregivers to join one of two focus groups to gather information about their experiences. A member of the research team also invited participants during two regularly scheduled caregiver support groups conducted by the adult day center. A total of 11 caregivers responded, and 10 caregivers participated.

\subsection{Data collection, procedures, and analysis}

\subsubsection{Quantitative}

The Kingston Caregiver Stress Scale (KCSS) was used to collect quantitative data. ${ }^{[19,20]}$ The KCSS is a brief, multidomain assessment of caregiver stress with support for reliability and validity. ${ }^{[19]}$ The scale contains 10 items which measure three domains of stress: caregiving, family, and financial. Items are measured on a 5-point Likert scale, ranging from $1=$ "Feeling no stress" to 5 = "Extreme stress." Total scores on the KCSS range from 10 to 50, with higher scores indicating more stress. Total possible domain scores for "caregiving issues" (7-item), "family issues" (2-item), and "financial issues" (1-item) are 35, 10, and 5 respectively. Participants completed the KCSS and a short demographic survey developed by the team at the start of each focus session. Data were analyzed using SPSS 25 (IBM Corporation, Armonk, New York). Descriptive statistics (frequencies, percentages, means, standard deviations, and Cronbach's alpha) were used to analyze the data.

Published by Sciedu Press

\subsubsection{Qualitative}

Using the literature and the framework of caregiver resilience, students developed open-ended questions for the focus groups. Examples of questions included: "Tell us about your experience of caring for your loved one" and "How has the adult day center affected your role as a caregiver?" Following training on focus group methodology, undergraduate members of the team acted as group facilitators. As suggested by the adult day center director, each focus group was organized to include a proportional number of male and female participants. Through experience, the director learned that male caregivers were often not comfortable talking during support sessions offered by the center, especially when proportionally more female caregivers were present. Therefore, focus sessions were planned so male caregivers were not in the minority in either group to allow for greater comfort in sharing their experiences.

Each focus group session lasted approximately 60-90 minutes and was audio-recorded. As a thank you for participating, all caregivers were given a $\$ 25.00$ gift card to a local merchant at the end of each focus group. Audio recordings were transcribed verbatim by a professional service. Using content analysis, all transcripts were analyzed by each member of the team and collectively as a group to determine the common themes. ${ }^{[21]}$

\subsection{Ethical considerations}

The study received exempt status from the institutional review board at the university.

\section{RESUlts}

\subsection{Caregiver characteristics}

The majority of caregivers were over 65 years of age, male $(60 \%)$, and white $(90 \%)$ (see Table 1). Fifty percent were employed outside the home. On average, the participants provided care for four years and brought their family member to the adult day center for approximately one year. One-half of the caregivers $(50 \%)$ were responsible for the care of someone else and received assistance in the caregiver role (60\%) beyond the adult day center. Top reasons for the family caregiver to use the adult day center were to socialize (40\%) and work $(40 \%)$. The persons with dementia receiving care were spouses (40\%), parents (40\%), and children of the caregivers $(20 \%)$.

\subsection{Quantitative data}

Participants reported experiencing moderate levels of caregiving stress according to the KCSS in all three domains (M $=30.5, \mathrm{SD}=9.7)$. Internal consistency for the KCSS in this sample was $r=.92$. Three items related to the domain of care 
giving issues on the KCSS were most stressful: "feelings of being overwhelmed, over worked, and/or overburdened" $(\mathrm{M}=3.75, \mathrm{SD}=1.16)$, "changes in your social life" $(\mathrm{M}$ $=3.75, \mathrm{SD}=.46$ ), and "concerns regarding the future care needs of your spouse/relative" $(\mathrm{M}=4.0, \mathrm{SD}=.76)$. Least

Table 1. Sample characteristics of family caregivers $(\mathrm{N}=10)$

\begin{tabular}{|c|c|c|c|c|c|}
\hline Variable & Mean & SD & Range & $\mathbf{n}$ & $\%$ \\
\hline Age & 65.0 & 10.58 & $46-84$ & & \\
\hline \multicolumn{6}{|l|}{ Gender } \\
\hline Male & & & & 6 & 60 \\
\hline Female & & & & 4 & 40 \\
\hline \multicolumn{6}{|l|}{ Employment } \\
\hline Full-time & & & & 2 & 20 \\
\hline Part-time & & & & 3 & 30 \\
\hline Retired & & & & 5 & 50 \\
\hline Number of years providing care & 4.2 & 3.00 & $1-10$ & & \\
\hline Number of years using adult day center & 1.3 & 0.98 & $0-3$ & & \\
\hline \multicolumn{6}{|l|}{ Received help from another person/service } \\
\hline None & & & & 3 & 30 \\
\hline Family & & & & 4 & 40 \\
\hline Hired caregiver/assistant & & & & 2 & 20 \\
\hline Blank & & & & 1 & 10 \\
\hline \multicolumn{6}{|l|}{ Responsible for the care of someone else } \\
\hline None & & & & 4 & 40 \\
\hline Handicapped child & & & & 1 & 10 \\
\hline Children & & & & 1 & 10 \\
\hline Mother & & & & 2 & 20 \\
\hline Wife & & & & 1 & 10 \\
\hline Blank & & & & 1 & 10 \\
\hline \multicolumn{6}{|l|}{ Reason for using adulty day center } \\
\hline Take care of personal health & & & & 2 & 20 \\
\hline Provide activities/socialization for person with dementia & & & & 3 & 30 \\
\hline Socialize & & & & 4 & 40 \\
\hline Work & & & & 4 & 40 \\
\hline Respite & & & & 3 & 30 \\
\hline Complete errands & & & & 3 & 30 \\
\hline Family responsibilities & & & & 1 & 10 \\
\hline
\end{tabular}

\subsection{Qualitative data}

Four themes emerged from the focus groups: (a) common emotional responses, (b) benefits of adult day services, (c) overwhelming impact on daily life, and (d) caregiver social isolation. For the "most common emotional responses", participants described a variety of emotions in varying degrees, including feelings of grief, guilt, denial, regret, and despair. One participant spoke about the despair of the illness trajectory: "Because I think the hardest thing, I had to deal with was it's not going to get any better. There is no cure. I have to accept that... it's only going to get worse." Denial was also a common response; one participant stated: "But everyone was in denial, okay, for the most part. Everyone just noticed stressful items were: "having any conflicts within your family over care decisions" $(\mathrm{M}=1.75, \mathrm{SD}=.89)$ from the family issues domain and "having any financial difficulties with care giving" $(\mathrm{M}=1.75, \mathrm{SD}=.89)$ from the financial issues domain. that she was a little forgetful, but nobody wanted to say that it was a more serious problem." Another participant directly connected emotions with grief: "I'd be crying every day. It's mourning. There's grief. It's a grief, and it's continuous." Two participants spoke about having to deal with worsening, aggressive behaviors and one stated: "I didn't know how to handle when she starts beating on you... But I always felt that was one thing I wish I knew better to handle." The participants regretted not knowing how to manage the physically aggressive behaviors but took solace in knowing that the loved one was not aware of what he or she was doing.

The second theme was "benefits of adult day services". Par- 
ticipants described feelings of gratitude for the security and peace of mind that ADS provide which in turn helped promote caregiver resilience and the ability to maintain some normal day-to-day activities. One participant stated: "So, they're a godsend, because that's a break for me. I try to work during those hours." Using the center allowed participants time for themselves, to exercise or run errands: "I was able to get out and at least run, go to the YMCA.... Because as you know, there's a lot of stress." Knowing their loved one was safe provided comfort: "It gives you peace of mind. I mean, there's a lot to be said for the peace of mind of who they're with and they are safe." Participants agreed about the need for ADS and the ability to count on the staff. As one participant described, and others agreed: “...it's the best thing I ever did... It saved me."

Participants expressed concerns with role overload that changed their daily lives. Not only did the caregiver role impact them, but the role impacted family members. These ideas were the third theme "overwhelming impact on daily life". One participant connected the impact directly to family needs: "And my kids, sometimes I feel bad that it's compromising kind of their - I don't know social lives." Another participant talked about the daily care needs of their loved one: "You have to take over everything", and another: "Grocery shopping, making food, sleeping in a chair next to his bed. I had to you know, learn everything..." There were many examples of how the day-to-day caregiver role impacted the caregiver's daily lives and their family members. The caregivers had to re-arrange their lives progressively as the disease continued. Participants described the eventual need to place their loved one in an agency for continuous care outside of the home.

The fourth theme was "caregiver social isolation". Participants expressed concerns of feeling disengagement from their lives and social connections. "You have to cut back on things you love. You can't do the hobbies you used to do. . . meet the friend for lunch on any given day. You can't do those simple things that used to bring you a little bit of joy." Some even expressed feelings of being a burden to their friends and not connecting with them: "You don't want to ruin somebody else's time, because usually that topic comes up." Dementia and taking care of a loved one was a stressful discussion for their friends, so the caregivers would avoid the conversations. The friends did not always know how to be supportive, and the caregivers disengaged as a result.

\section{Discussion}

\subsection{The collaborative research team}

Findings from this research further support undergraduate student-faculty collaborative research models. This pilot study was effectively carried out by the undergraduate nursing students. The student researchers managed the project from literature search to dissemination of findings. Not only did the students gain experience in qualitative and quantitative research methodologies, the team was able to add to the growing body of literature on caregiver resilience. The team chose to address this question because of the positive clinical experiences gained by the students at ADS. The students presented their work at a regional research conference via podium and poster sessions. In addition to participating in the research process, the students learned valuable insight into dementia care. They can apply these findings as they embark on their nursing careers and can provide guidance to other clinicians regarding the benefits of ADS.

\subsection{Caregiver role}

Quantitative and qualitative data converged and demonstrated the stressfulness of the caregiver role impacting day-to-day functioning for these participants. Through the use of the $\operatorname{KCSS}^{[19,20]}$ and focus groups, the participants identified how the role of the caregiver impacted their emotional health and how they were burdened daily with the many demands of providing care to a family member with dementia. Not only did the demands of care impact their life at home, the demands impacted life outside the home such as work and socialization.

The most stressful and least stressful issues related to caregiving were similar to previous research using the KCSS. ${ }^{[20]}$ In the current study, participants found being overwhelmed, overworked and/or overburdened, and concerns over future care needs as the most stressful aspects of caregiving, while financial difficulties were the least stressful. While providing care to a person with dementia may include financial repercussions ${ }^{[6,9]}$ participants in this study did not report this issue. It could be that these caregivers were able to manage the costs associated with using the adult day center or that the benefits offered by the respite service outweighed any financial burden. In addition, this adult day center provided services regardless of ability to pay potentially attenuating financial issues.

Through focus group interviews, the students identified four themes of common emotional responses, benefits of ADS, overwhelming impact on daily life, and caregiver social isolation which were similar to findings in the literature. ${ }^{[8,14,17,22]}$ The challenges and struggles of dementia caregiving were evident. The experiences described by the caregivers explained a complex role and how they had to balance a variety of demands such as jobs and child-rearing. The changes in role came on gradually until the caregivers had to accept the "unexpected career". ${ }^{[8]}$ Not only did the caregivers speak 
of how the role changed their lives, they also spoke of how use of the adult day center helped them maintain resilience. The caregiver role is ongoing and there is the potential for multiple physical, emotional, and financial impacts on daily life that affect families as well. ${ }^{[8]}$ Caregivers in this study provided care for an average of four years. Caregivers over longer periods of time often manage to develop resilience and better manage day-to-day stressors. ${ }^{[16]}$

Maintaining day-to-day activities and functioning promotes resilience and supports healthier mental, emotional, social, and physical well-being, ${ }^{[8]}$ as well as, decreasing the burden of caregiving. ${ }^{[23]}$ The participants in this study shared how the use of the adult day center was beneficial in their lives. They were able to maintain normalcy by continuing basic activities such as exercising, shopping, and working. Respite services, such as ADS, provided caregivers with opportunities for self-care and the ability to perform daily tasks, resulted in decreased emotional burden, and promoted resiliency in these participants.

While planning this pilot study, the team learned an important factor to consider when conducting support groups with caregivers. The director of the adult day center used in this study described a concern not directly discussed in the literature. Male caregivers were hesitant to share experiences during support sessions, especially when proportionally more female caregivers were present. While the literature failed to provide explanations for this identified phenomenon, the literature reports that some men are reluctant to seek help, or share feelings of stress, due to traditional male values. ${ }^{[24]}$ However, in another study, men reported wanting to talk with other men in the caregiver role. ${ }^{[25]}$ Therefore, the team recommends future research should consider a specific focus on men's participation and use of support groups.

\subsection{Limitations}

Limitations of the current study included the small, homogeneous, convenience sample which limits generalizability; however, the mixed method design permits a more comprehensive and synergistic use of the data. While the demographic characteristics of the participants were not diverse, the participants did reflect the community of those living in the area and reflected those utilizing the adult day center. Data about each family member with dementia was not collected, and unique characteristics of these individuals may have impacted the caregiver's perceptions and experiences. The pilot methodology using a student-faculty collaborative team was a successful approach to assessing the caregiver role and supports replication. Based on these initial results, collecting data from more diverse participants over time and recruiting from more ADS to increase generalizability is warranted.

\subsection{Implications for practice}

A clinical intervention for caregivers should include an educational component anticipating the barriers caregivers may face when learning about ADS. It is important to anticipate future care needs, what resources are available, and who can assist the caregiver with decision-making. Use of a screening tool by providers, such as the KCSS, ${ }^{[19,20]}$ may be useful for opening discussions about how the caregiver is coping and focusing directly on areas of burden. Knowing what types of caregiver stress are predominant can alert providers to suggest use of ADS and other community resources to support resilience. Providers should help caregivers develop skills such as problem solving, managing emotions, and replacing losses. ${ }^{[10]}$ Resilience does not protect caregivers from distress, but it can help them recover from setbacks. ${ }^{[26]}$ Future research should assess caregivers' experiences longitudinally. Additionally, it is important to explore the impact of ADS on the person with dementia, focusing on socialization and opportunities for increased activity. Students were able to participate with activities and care provided at the adult day center and believed it was important to determine a method of assessing outcomes for the person with dementia. Findings from this study should be used to encourage nurses in both in-patient and out-patient settings to potentially refer family caregivers to ADS. Referrals provide a potential means of preventing the stress of the caregiver role and allow respite for caregivers whose resilience is waning.

\section{Conclusion}

Nursing students often lack opportunities to actively participate in and lead ongoing research as undergraduates. An effective approach is mentoring undergraduate students through a student-faculty collaborative model that expects the students to drive the research process. Nursing students have the critical thinking and leadership skills needed to design, implement, and evaluate a program of research when mentored by faculty. The findings from the collaborative team determined respite services, such as adult day centers, provide caregivers opportunities for self-care, the ability to perform daily tasks, and results in decreased emotional burden which supports resilience. Nurses should educate the public on available resources, such as adult day services, when caring for someone with dementia. As future practitioners, these students will be more inclined to participate in best practice because of their experience on a student-faculty collaborative team.

\section{ACKNOWLEDGEMENTS}

Undergraduate team members: Madissen Brookshire-Green, 
Guadalupe Ortiz, and Olivia Smith were senior nursing students; Emma Kamp and Kayleigh Willett were juniors; and Madison Ling, Keegan Maris, and Isabella Portugal were sophomores on the team. Research funding was received from the Kreft Endowment for the Advancement of Nursing
Science at Valparaiso University. The authors declare no conflict of interest.

\section{CONFLicts OF InTEREST Disclosure}

The authors declare that there is no conflict of interest.

\section{REFERENCES}

[1] Kessler TA, Alverson EM. Mentoring undergraduate nursing students in research. Nursing Education Perspectives. 2014; 35: 262-264. PMid:25158423 https://doi.org/10.5480/11-555.1

[2] Kurtz CP, Kessler TA. An undergraduate collaborative team model to engage nursing students in research. Journal of Nursing Education \& Practice. 2017; 7(7): 112-118. https://doi.org/10.5430/jnep .v7n7p112

[3] Wheeler EC, Hardie T, Schell K, et al. Symbiosis: undergraduate research mentoring and faculty scholarship in nursing. Nursing Outlook. 2008; 56: 9-15. PMid:18237619 https://doi .org/10.101 $6 / j$.outlook. 2007.09.001

[4] Halcomb E, Smyth E, Moxham L, et al. Bachelor of Nursing 244 Honours programs in Australia: current trends and key challenges. Collegian. 2018; 25(4): 429-434. https://doi.org/10.1016/j. colegn.2017.11.003

[5] World Health Organization [Internet]. Dementia; 2019 Sept [cited 2020 May 22] Available from: https: //www . who. int/news-roo $\mathrm{m} /$ fact-sheets/detail/dementia

[6] Alzheimer's Association [Internet]. Alzheimer's disease facts and figures; 2020 [cited 2020 May 22]. Available from: https ://www. alz.org/alzheimers-dementia/facts-figures

[7] Czekanski K. The experience of transitioning to a caregiving role for a family member with Alzheimer's disease or related dementia. American Journal of Nursing. 2017; 117(9): 24-32. PMid:28806278 https://doi.org/10.1097/01. NAJ .0000524517.60352.84

[8] Roberts E, Struckmeyer KM. (The impact of respite programming on caregiver resilience in dementia care: a qualitative examination of family caregiver perspectives. The Journal of Health Care Organization, Provision, and Financing. 2018; 55: 1-11. PMid:29424252 https://doi.org/10.1177/0046958017751507

[9] Warchol-Biedermann K, Mojs E, Gregersen R, et al. What causes grief in dementia caregivers? Archives of Gerontology and Geriatrics. 2014; 59: 462-467. PMid:25042576 https://doi.org/10.1016/ j. archger. 2014.05.013

[10] Jones SM, Killett A, Miosha E. The role of resilient coping in dementia carers' wellbeing. British Journal of Neuroscience Nursing. 2019; 15(1): 6-12. https://doi.org/10.12968/bjnn.2019.15.1.6

[11] Parks S, Novielli K. A practical guide to caring for caregivers. American Family Physician. 2000; 62(12): 2613-22.

[12] Fonareva I, Oken B. Physiological and functional consequences of caregiving for relatives with dementia. International Psychogeriatrics 2014; 26(5): 725-47. PMid:24507463 https ://doi .org/10.101 7/S1041610214000039

[13] Meuser T, Marwit S. A comprehensive stage-sensitive model of grief in dementia caregiving. Gerontologist. 2001; 41(5): 658-70. PMid:11574711 https://doi.org/10.1093/geront/41.5.65 8

[14] Clarke P, Shaw E, Villalba J, et al. Therapeutic interactions to enhance the mental health and wellness of dementia caregivers and patients. Journal of Gerontological Nursing. 2013; 39(11): 7-10. PMid:24066787 https://doi.org/10.3928/00989134-20130 916-06

[15] Cherry MG, Salmon P, Dickson JM, et al. Factors influencing the resilience of carers of individuals with dementia. Reviews in Clin Gerontology. 2013; 23: 251-266. https://doi.org/10.1017/S0 959259813000130

[16] Lopes da Rosa RD, Simões-Neto JP, Santos RL, et al. Caregivers' resilience in mild and moderate Alzheimer's disease. Aging \& Mental Health. 2020; 24: 250-258. PMid:30499333 https://doi .org/10 $.1080 / 13607863.2018 .1533520$

[17] Kim K, Zarit S, Femia E, et al. Kin relationship of caregivers and people with dementia: stress and response to intervention. International Journal of Geriatric Psychiatry. 2012; 27: 59-66. PMid:21322030 https://doi.org/10.1002/gps.2689

[18] Doorenbos AZ. Mixed methods in nursing research: an overview and practical examples. Kango Kenkyu. 2014; 47(3): 207-217.

[19] Hopkins RW, Kilik LA. The Kingston caregiver stress scale (KCSS); 2016 [cited 2019 Aug 20]. Available from: http://nebula.wsi mg. com/979c665ffd41f5c5a0f8987c3817d273?AccessKeyI $\mathrm{d}=954 \mathrm{~A} 289 \mathrm{~F} 7 \mathrm{CDF} 75707 \mathrm{C10}$ \&disposition=0\&alloworigin=1

[20] Sadak T, Zdon S, Ishado E, et al. Potentially preventable hospitalizations in dementia: family caregiver experiences. International Psychogeriatrics. 2017; 29(7): 1-11. PMid:28349858 https: //doi.org/10.1017/S1041610217000217

[21] Elo S, Kyngäs H. The qualitative content analysis process. Journal of Advanced Nursing. 2007; 62(1): 107-115. PMid:18352969 https://doi.org/10.1111/j.1365-2648.2007.04569.x

[22] Pinquart M, Soreson S. Helping caregivers of persons with dementia: which interventions work and how large are their effects? International Psychogeriatrics. 2006; 18(4): 577-95. PMid:16686964 https://doi.org/10.1017/S1041610206003462

[23] Anand K, Dhikav V, Sachdeva A, et al. Perceived caregiver stress in Alzheimer's disease and mild cognitive impairment: a case control study. Annals of Indian Academy of Neurology. 2016; 19(1): 58-69. PMid:27011630 https://doi.org/10.4103/0972-2327.1676 95

[24] Baker KL, Robertson N, Connelly D. Men caring for wives or partners with dementia: masculinity, strain and gain. Aging \& Mental Health. 2010; 14: 319-327. PMid:20425651 https : //doi .org/10 $.1080 / 13607860903228788$

[25] Knutsen H, Råholm M. The dialectic movement between suffering and reconciliation: male caregivers' experience of caring for their wives suffering from dementia. International Journal for Human Caring. 2009; 13: 50-56. https://doi.org/10.20467/1091-5710. 13. 4.50

[26] Jones SM, Miosha E, Killett A. Coping but not allowing the coping to be everything: resilience in informal dementia care. Health and Social Care in the Community. 2019; 27: e289-e297. PMid:30844124 https://doi.org/10.1111/hsc. 12732 